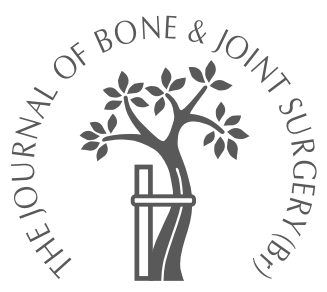

S. Fuerderer,

K. Eysel-Gosepath,

U. Schröder,

K.-S. Delank,

P. Eysel

From the Cologne

University Hospitals, Köln, Germany

S. Fuerderer, MD, Senior Registrar

K. Eysel-Gosepath, MD

$\mathrm{PhD}$, Senior Registrar

K.-S. Delank, MD, Registrar

P. Eysel, MD, PhD,

Consultant, Head of

Department

Department for Orthopaedic Surgery

U. Schröder, MD, Senior

Registrar

Department for ENT Surgery

Cologne University

Hospitals, Joseph

Stelzmannstrasse 9, D-50931

Köln, Germany.

Correspondence should be sent to Dr S. Fuerderer.

(c)2004 British Editorial

Society of Bone and

Joint Surgery

doi:10.1302/0301-620X.86B6.

$14933 \$ 2.00$

$J$ Bone Joint Surg [Br]

2004;86-B:837-40.

Received 8 September 2003;

Accepted 1 October 2003

\section{Retro-pharyngeal obstruction in association with osteophytes of the cervical spine}

We describe five patients with cervical spondylosis and large anterior osteophytes causing pharyngeal compression. All had dysphagia, two had obstructive sleep apnoea and another two had dyspnoea and stridor on inspiration. One, with perforation of the pharynx, required emergency tracheostomy. Only three had pain in the neck or arm.

Compression of the retroglottic space was confirmed in all patients by pharyngoscopy and in all the symptoms were relieved by excision of the osteophytes. Three also underwent intervertebral fusion. One had some persistent sleep apnoea.

Cervical spondylosis may cause dysphagia, a sensation of retropharyngeal globus and stridor. ${ }^{1,2}$ The posterior wall of the pharynx is separated from the vertebral column only by a thin layer of soft tissue. Below the level of the glottis, the oesophagus lies in front of the vertebral bodies from C4 caudally, with the trachea anterior. Thus cervical pathology above C4 may compress the pharynx and lesions below may cause either oesophageal or pharyngeal symptoms. Although the oesophagus is collapsed, except during swallowing, the diameter of the pharynx remains constant. In the supine position, as during sleep, retropharyngeal pathology may cause collapse of the airway. Hyperostotic spondylosis (Forestier's disease) may present as dysphagia, haemoptysis, the sensation of airway obstruction by a foreign body or recurrent laryngeal nerve palsy. ${ }^{3-11}$ There has been one case report of retropharyngeal compression presenting as sleep apnoea. ${ }^{12}$

\section{Patients and Methods}

Five patients with anterior cervical osteophytes causing local compressive symptoms presented between 2000 and 2002. There were four men and one woman with a mean age of 76 years (48 to 81 ). Three had neck pain. Two presented to the ENT department with dyspnoea and dysphagia, and one with acute dyspnoea required a tracheostomy. Three patients had disturbance of sleep; two had already undergone investigation for sleep apnoea. In the third, a presumptive diagnosis of upper airways resistance syndrome (UARS) with incomplete collapse of the airways was made. All

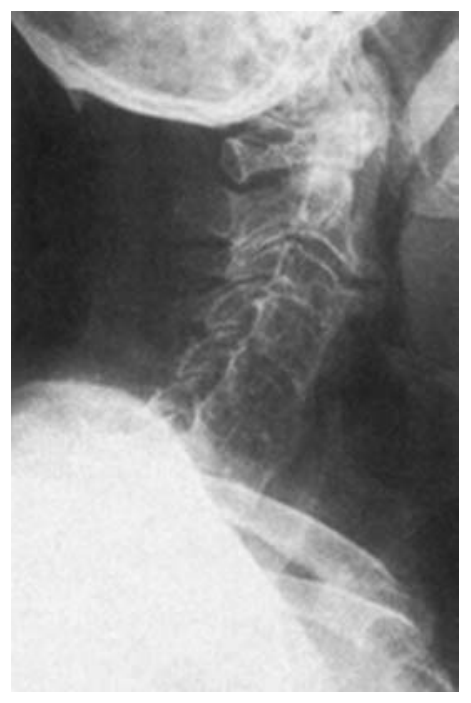

Fig. 1

A lateral cervical radiograph of a 75year-old patient with spontaneous fusion of the lower cervical spine, large osteophytes at $\mathrm{C} 2 / 3$ and compression of the pharynx.

patients complained of a globus sensation and difficulty in swallowing. On examination, in each patient, there was only minor limitation of movement of the neck compatible with their age. Three had neck pain, and one had pain which radiated to the arm. All had normal motor function and sensation. Two also had carpal tunnel syndrome diagnosed by EMG and nerve conduction studies.

All patients had radiographs of the cervical spine and CT or MRI in order to assess the prevertebral soft-tissues. Tracheal radiographs or 


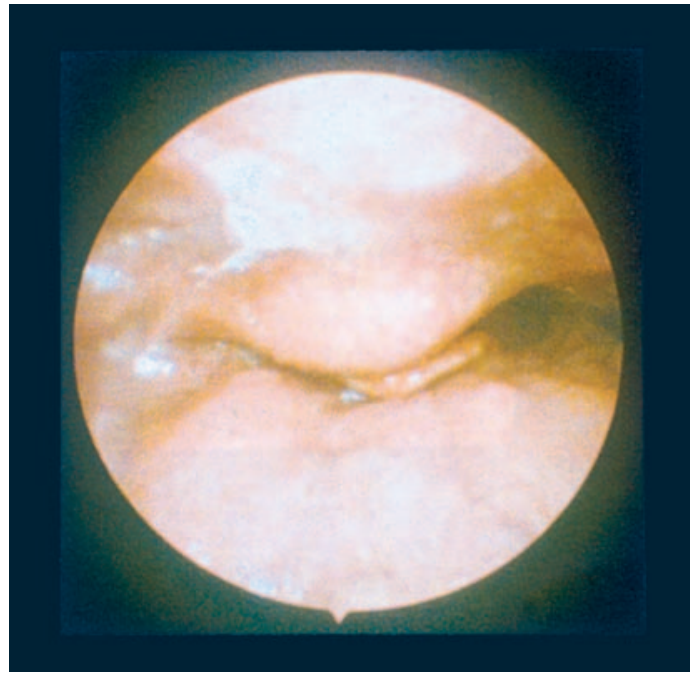

Fig. 2

Endoscopy showing compression of the glottis.

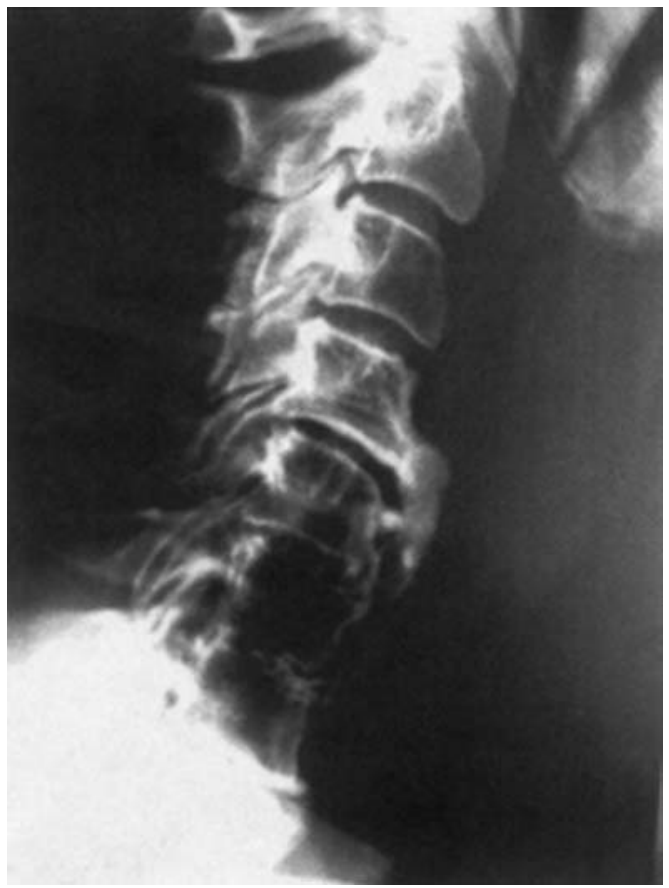

Fig. 4

A lateral cervical radiograph of a patient with Forestier's disease with an anterior osteophyte which projected 18 $\mathrm{mm}$ from the vertebral body.

oesophageal contrast studies were also undertaken. Three patients had undergone polysomnography with respect to the sleeping position, and panendoscopy of the pharynx, hypopharynx, larynx and trachea in the ENT department.

All underwent surgery with excision of the osteophytes and in order to document the effect of decompression, panendoscopy was repeated post-operatively.

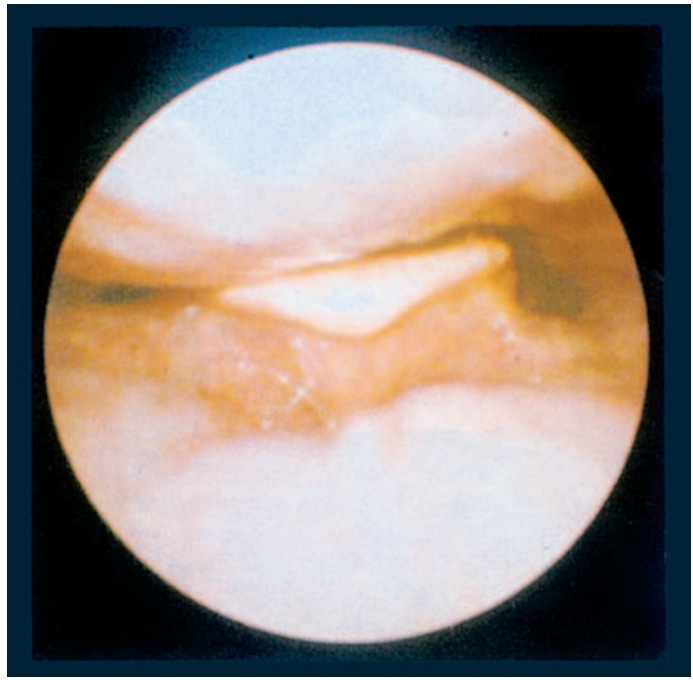

Fig. 3

Endoscopy after removal of the osteophyte showing relief of the compression.

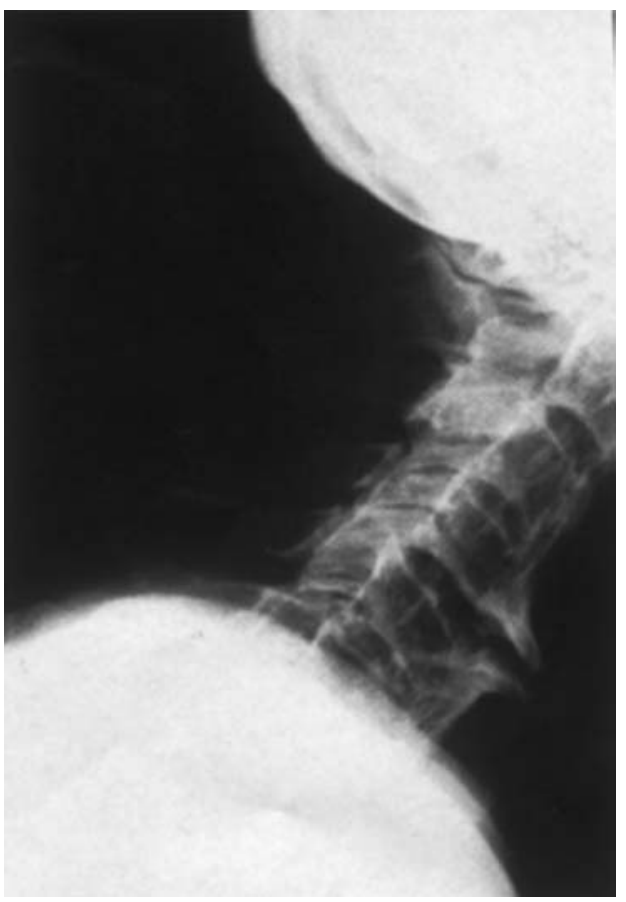

Fig. 5

Patient with Forestier's disease and an anterior osteophyte at $\mathrm{C} 5 / 6$ projecting $18 \mathrm{~mm}$ from the vertebral body.

\section{Results}

All patients had degenerative disc disease from C2/3 to C7/ T1 with large anterior osteophytes. Three had Forestier's disease. One, with a pharyngeal fistula had prevertebral osteophytes throughout the cervical spine and was diagnosed as having diffuse idiopathic skeletal hyperostosis (DISH). 


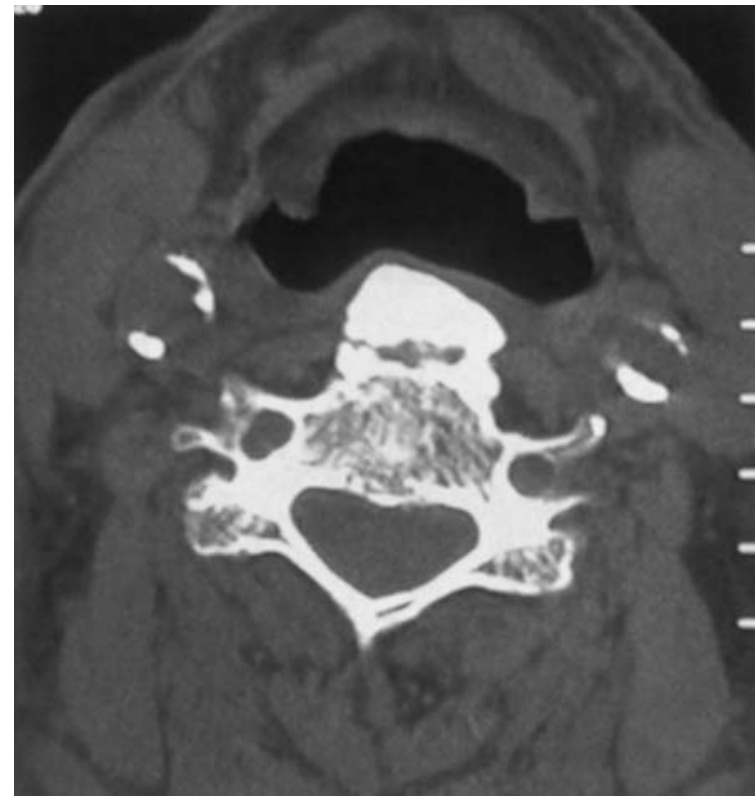

Fig. 6

A CT scan showing compression of the pharynx.

CT or MRI confirmed a posterior impression of the upper airways. There was no significant spinal stenosis at the degenerative segments.

All underwent endoscopy in the ENT department in order to localize the level of compromise of the airway as either supra- or sub-glottic stenosis. In the patient with DISH, the osteophytes had caused postcricoid perforation of the posterior pharyngeal wall.

Surgery consisted of excision of the osteophytes and if there was associated instability, intervertebral fusion was undertaken using a titanium cage (WING, medinorm, Braunshausen, Germany), filled with $\beta$-tricalciumphosphate (CERASORB, Ceramtech, Plochingen, Germany).

The different operative patterns are described in detail. Spondylosis at C2/3. A 75-year-old man presented with dyspnoea, dysphagia and a sensation of globus. On examination there was stridor on inspiration. The range of movement of the cervical spine was reduced due to spontaneous fusion of the upper levels secondary to Forestier's disease. He had non specific neck pain but no pain in the arm. Radiographs revealed anterior osteophytes projecting 14 $\mathrm{mm}$ from the vertebral body and causing compression of the retroglottic space (Fig. 1). At panendoscopy there was severe compromise at this site (Fig. 2). After removal of the osteophytes further endoscopy confirmed relief of this compression (Fig. 3). He was asymptomatic after surgery.

Spondylosis at C4/5. Two patients with multi-level disc disease had projection of anterior osteophytes at C4/5 by 12 and $13 \mathrm{~mm}$ respectively (Figs 4 and 5). One had Forestier's disease. They were aged 75 and 81 years; one had sleep apnoea and one VARS. Neither had radicular pain; one had

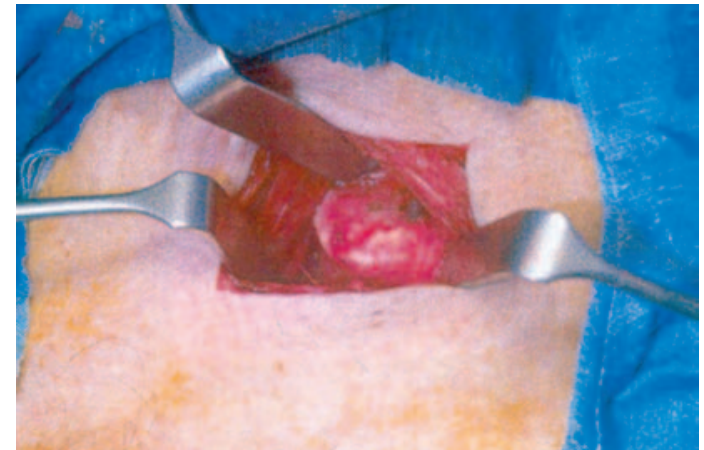

Fig. 7

Intra-operative view of the osteophyte.

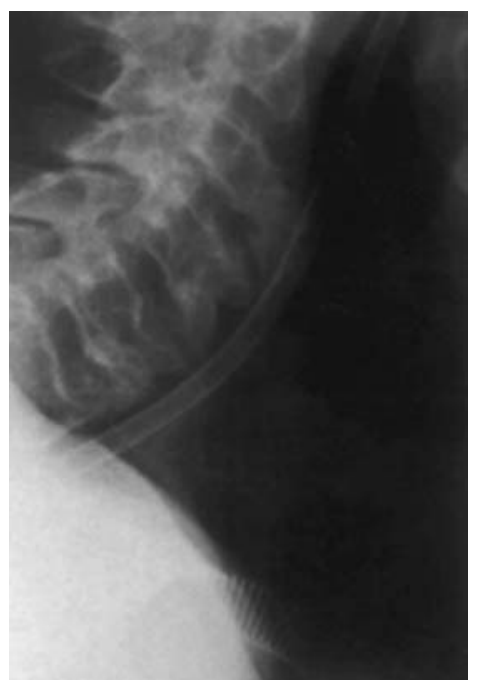

Fig. 8

An intra-operative radiograph showing the multisegmental ossification of the patient with DISH. The osteophytes projected 16 $\mathrm{mm}$ into the retropharyngeal space.

mild neck pain. CT showed compression of the supraglottic space (Fig. 6). At surgery a large osteophyte was removed (Fig. 7) and interbody fusion performed in each patient.

Spondylosis at C5/6 and C6/7. The female patient had twolevel degenerative disease with anterior spondylosis and spinal stenosis. She complained of neck and radicular pain as well as dysphagia and vertigo. A diagnosis of sleep apnoea had been made. She had coronary artery disease with mitral valve stenosis and aortic incompetence. The osteophytes projected $8 \mathrm{~mm}$ into the retrotracheal space causing compression of the trachea. Excision of the osteophytes and fusion relieved the dysphagia and radicular pain but some sleep apnoea persisted. Further polysomnography showed, that in the supine position the phases of apnoea were fewer. 
Multilevel anterior spondylosis. This patient presented to the ENT department with dyspnoea and stridor. A tracheostomy was required because of pharyngeal perforation, paralysis of the vocal cords and oedematous supraglottic airway obstruction. Cervical radiographs (Fig. 8) and CT showed the changes of DISH with osteophytes from C3 to T1. The osteophytes were excised and the pharynx repaired. A nasogastric tube was retained until the repair had healed and the tracheostomy tube was removed one week after surgery. He made a good post-operative recovery with partial resolution of the paralysis of the vocal cords.

\section{Discussion}

Cervical spondylosis usually presents as neck and radicular pain. The close relationship between the spinal canal and its neural contents only allows space for small osteophytic changes without neurological impairment. Thus, compromise of the canal is the most common indication for surgery in the cervical spine. The size of the retropharyngeal space is however very variable despite the close relationship of the vertebral column to the pharyngeal structures. ${ }^{13}$ Anterior osteophytes rarely cause symptoms due to compression of the pharynx, oesophagus or upper airways. Such symptoms more often follow local surgery. ${ }^{14}$ Retropharyngeal pathology may cause dysphagia or abnormal salivation, and involvement of the upper airways presents as dyspnoea, hoarseness, stridor, or sleep apnoea. ${ }^{15-21}$

UARS is difficult to diagnose as the increased effort required to breathe during sleep may only be demonstrated by measurements of oesophageal pressure. Where there are large retropharyngeal masses stridor on inspiration causes compromise of the upper airways. ${ }^{22}$

In order to identify the lesion, pressure measurements at different levels are used to classify retrovelar, retrolingual and combined obstructive sleep apnoea. ${ }^{23,24}$ Sleep apnoea has been described as a possible consequence of cervical spondylosis in a case report. ${ }^{12}$ Polysomnography is essential in the diagnosis of sleep apnoea; there have been no reports of appropriate studies in patients with cervical spondylosis.

Neck pain was the presenting symptom in three patients, in all of whom the symptoms of anterior soft tissue compression were considered more disabling. Affections of the vocal cord are rare. Paresis of the recurrent laryngeal nerve may be associated with tumours, infection and local lymphadenopathy due, for instance, to sarcoidosis or silicosis. ${ }^{11,14,17,25-27}$ Postcricoid inflammation may also cause bilateral vocal cord paresis. ${ }^{28}$ There is one case report of vocal cord palsy in a patient with Forestier's disease in the literature. ${ }^{29}$ In our patients one with this disorder had a palsy of the left vocal cord due to pressure on the recurrent laryngeal nerve.

Appropriate ENT examination is important in these patients in order to exclude other retropharyngeal pathology.
No benefits in any form have been received or will be received from a commercial party related directly or indirectly to this article.

\section{References}

1. Benhabyles M, Brattstrom H, Sunden G. Dysphagia and dyspnea as complications in spondylarthritis anklyopoetica with cervical osteophytes. Acta Orthop Scand 1970;41:396-401.

2. Grasshof H, Motsch C, Mahlfeld K. Vertebragenic dysphagia. Zentralb/ Chir 1999; 124:1041-4.

3. Humphreys SC, Hodges SD, Eck JC, Griffin J. Dysphagia caused by anterior cervical osteophytes: a case report. Am J Orthop 2002;31:417-19.

4. Maiuri F, Stella L, Sardo L, Buonamassa S. Dysphagia and dyspnea due to an anterior cervical ostephyte. Arch Orthop Trauma Surg 2002;122:245-7.

5. Ozgocmen S, Kiris A, Kocakoc E, Ardicoglu 0. Osteophyte-induced dysphagia: report of three cases. Joint Bone Spine 2002;69:226-9.

6. Bruno E, Alessandrini M, De Angelis E. Giant cervical hyperostosis of the prevertebral space: presentation of two cases and review of the literature. Acta Otorhinolaryngol Ita/ 1996;16:532-6.

7. Demuynck K, Van Calenbergh F, Goffin J, et al. Upper airway obstruction caused by a cervical osteophyte. Chest 1995;108:283-4.

8. Alonso-Vielba J, Morais D, Matesanz A, Santos J. Distress of the airway due to vertebral ankylosing hyperostosis or Forestier-Rotes' disease. An Otorrinolaringol lbero Am 1994;21:159-67.

9. Papakostas K, Thakar A, Nandapalan V, O'Sullivan G. An unusual case of stridor due to osteophytes of the cervical spine (Forestier's disease). J Laryngol Otol 1999; 113:65-7.

10. Sidi J, Hadar T, Shvero J, et al. Respiratory distress due to diffuse cervical hyperostosis. Ann Otol Rhinol Laryngol 1987;96:178-81.

11. Hassard AD. Cervical ankylosing hyperostosis and airway obstruction. Laryngoscope 1984;94:966-8.

12. Hughes TA, Wiles CM, Lawrie BW, Smith AP. Case report: dysphagia and sleep apnoea associated with cervical osteophytes due to diffuse idiopathic skeletal hyperostosis (DISH). J Neurol Neurosurg Psychiatry 1994;57:384.

13. Schmäl F, Stoll W. Differential diagnosis and management of retropharyngeal space-occupying lesions. HNO 2002;50:418-23.

14. Apfelbaum RI, Kriskovich MD, Haller JR. On the incidence, cause, and prevention of recurrent laryngeal nerve palsies during anterior cervical spine surgery. Spine 2000;25:2906-12

15. Karlins NL, Yagan R. Dyspnea and hoarseness: a complication of diffuse idiopathic skeletal hyperostosis. Spine 1999;16:235-7.

16. Sen P, Flower N, Papesch M, Davis A, Spedding AV. A benign parathyroid cyst presenting with hoarse voice. J Laryngol Otol 2000;114:147-8.

17. Landau O, Chamberlain DW, Kennedy RS, Pearson FG, Keshavjee S. Mediastinal parathyroid cysts. Ann Thorac Surg 1997;63:951-3.

18. Mader R. Clinical manifestations of diffuse idiopathic skeletal hyperostosis of the cervical spine. Semin Arthritis Rheum 2002;32:130-5.

19. Aland JW. Retropharyngeal lipoma causing symptoms of obstructive sleep apnea. Otolaryngol Head Neck Surg 1996;114:628-30.

20. Di Girolamo S, Marinelli L, Galli A, Ottaviani F. Retropharyngeal lipoma causing sleep apnea syndrome. J Oral Maxillofac Surg 1998;56:1003-4.

21. Desuter G, Castelein S, de Toeuf C, Rombaux P, Hamoir M. Parapharyngeal causes of sleep apnea syndrome: two case reports and review of the literature. Acta Otorhinolaryngol Belg 2002;56:189-94

22. Hollandt JH, Kuhl S, Gabler R, Remmert S. Upper airway resistance syndrome (UARS): obstructive snoring. HNO 2000;48:628-34.

23. Fujita S. Obstructive sleep apnea syndrome: pathophysiology, upper airway evaluation and surgical treatment. Ear Nose Throat J 1993;72:67-72, 75-76.

24. Verse T, Pirsig W. Current aspects on diagnosis of sleep-related breathing disorders. HNO 2001:49:6-11

25. Povedano Rodriguez V, Seco Pinero MI, Jaramillo Perez J. Sarcoidosis as a cause of paralysis of the recurrent laryngeal nerve: presentation of a case. An Otorrinolaringol Ibero Am 1992;19:443-8.

26. Yoskovitch A, Kantor S. Cervical osteophytes presenting as unilateral vocal fold paralysis and dysphagia. J Laryngol Otol 2001;115:422-4.

27. Lardinois D, Gugger M, Balmer MVC, Ris HB. Left recurrent laryngeal nerve palsy associated with silicosis. Eur Respir J 1999;14:720-2.

28. Kasper D, Hermichen $\mathbf{H}$, Koster R, Schultz-Coulon HJ. Clinical manifestations of diffuse idiopathic skeletal hyperostosis (DISH). HNO 2002;50:978-83.

29. McCafferty RR, Harrison MJ, Tamas LB, Larkins MV. Ossification of the anterior longitudinal ligament and Forestier's disease: an analysis of seven cases. J Neurosurg 1995;83:13-17. 